\title{
Gynecological Cancer and Family Planning. A Prospective Study of a Group of Eighty-Eight Greek Women and Review of Literatures
}

\author{
Giannakopoulou $\mathrm{E}^{1}$ and Sofoudis $\mathrm{C}^{2 *}$ \\ ${ }^{1}$ Department of Midwifery, Aegean College, Greece \\ ${ }^{2}$ Department of Obstetrics and Gynecology, Konstandopoulio General Hospital, Greece
}

*Corresponding author: Chrisostomos Sofoudis, Department of Obstetrics and Gynecology, Konstandopoulio General Hospital Athens, Ippokratous 209, 11472, Athens, Greece.

Received Date: September 13, 2019

Published Date: September 19, 2019

\section{Abstract}

One of the major problems faced by modern women represents the gynecological cancer, comprising uterine, cervical, endometrial, ovarian and breast cancer.

Therefore, gynecological cancer can be also described as cancer of the female reproductive system. Nowadays, cancer consists the primary cause of death worldwide, displacing all coronary diseases and strokes.

Gynecological cancer constitutes around $20 \%$ of these cases, whereas mortality rates reach up to $13 \%$. When cancer is diagnosed in women of reproductive age, consult by specialists should be undertaken in order to inform the couple about the alternations in their lives, the options they have and discuss all possible scenarios.

In most cases, gynecological cancer does not only affect the health of the patient as an individual, but also her sexual life, her ability to procreate and her partner's life, in consequence. Although the treatment of cancer is of primary importance, the attending doctor should also examine the impact of the disease on fertility at the time of diagnosis and the damage caused by possible surgery, chemotherapy or radiotherapy.

In addition, consult of family planning should be offered to all couples, in order to inform them about contraceptive methods suitable for their individual cases as well as hereditary characteristics they might be interested in.

Several studies prove that the use of contraceptive pills increase the incidence of breast and cervical cancer, whereas others support that the incidence depends on the period of use and the chronological gap between contraception and cancer appearance.

Another variable that should be kept in mind is the type of hormonal contraception is used. Progestin-only oral contraceptives' action is supported by the suppression of ovulation, an inhibiting effect on the midcycle peaks of LH and FSH, an increase in cervical mucus viscosity, a reduction in the number and size of endometrial glands and a reduction in cilia motility in the fallopian tube.

On the other hand, combination oral contraceptives' dominant mechanism of action is to prevent ovulation, with the combination of the 2 steroids, estrogens and progesterone, which greatly increases their antigonadotrophic and ovulation-inhibitory effects.

The significance of this study lies in the knowledge around complications arising by certain contraceptive methods, as far as around the way cancer patients are informed about family planning and the evaluation for the need of alternations in the existing system.

Keywords: Gynecologic cancer; Family planning; Contraceptive methods

\section{Introduction}

Breast cancer represents the most common type of cancer among women worldwide and is referred to as second, after lung cancer. In fact, studies claim that one out of eight women will be diagnosed with breast cancer during her lifetime [1].
The most important risk factor is the existence of a positive family history, especially when this appears in first-degree relatives. The mutations of the tumor suppressor gene BRCA1, which is mounted on chromosome 17 have been implicated in an increased 
incidence of breast cancer and / or ovarian cancer (breast - ovarian syndrome) [2].

Early menarche, late menopause and advanced age of first pregnancy are factors that increase the risk of developing breast cancer. Nulliparous women or women with a first pregnancy after the age of 35 present 2-3 times greater risk of developing breast cancer, compared to those of childbearing for the first time before the age of 35 [3].

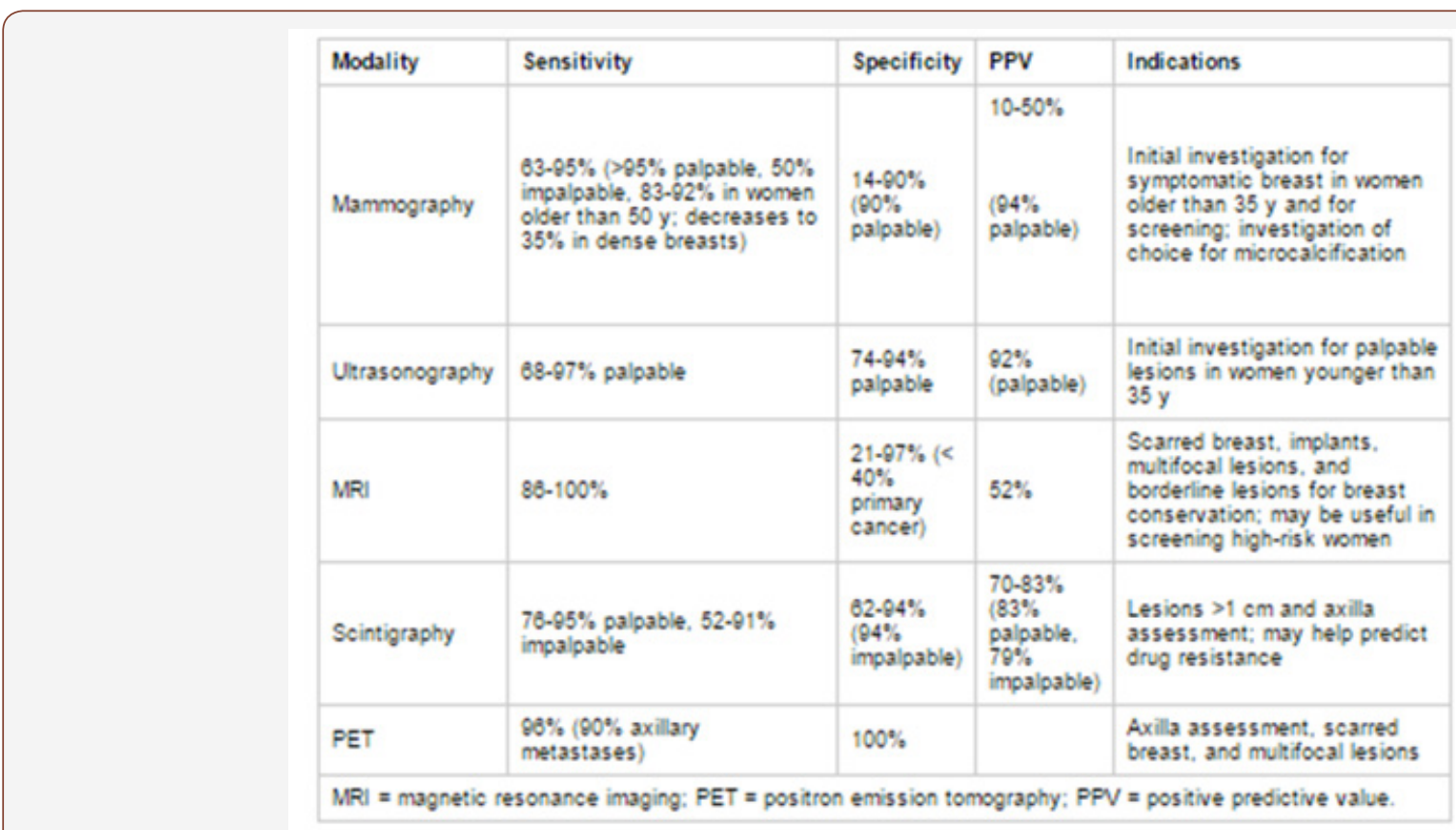

Figure 1: Breast imaging modalities.

Most efficient treatment of breast cancer consists prevention. Following table presents the accuracy of breast imaging modalities in relation to the indicative cases (Figure 1). As far as the environmental effects, the impact breast cancer is 3-4 times higher in industrialized countries than in less developed.

While most women are diagnosed with breast cancer after menopause, one woman in the third decade of her life in the United States shows a probability around $0.5 \%$ of developing breast cancer during reproductive period, which brings forth the effect of cancer treatment in future fertility and future pregnancy [4].

According to the US Census Bureau of Statistics, average age of onset of menopause for the American women is between the 50th and 52nd year of age. The mean age of women who experience amenorrhea after adjuvant chemotherapy varies between 38-46 years [5]. Probability of induced menopause by chemotherapy is directly related to age. The incidence of amenorrhea appears around $21 \%$ in younger patients but ranges from $49 \%$ to $100 \%$ in women over 40 years old [6]. Women with breast cancer, who wishes for a future pregnancy, should discuss about preservation of fertility at the time of diagnosis, prior to the commencement of treatment. Oocyte, embryo or ovarian tissue cryopreservation are the most commonly offered options [7].

Correlation between hormonal contraception and breast cancer development has not been verified and it is presented as a controversy. The hypothesis states that women receiving hormonal contraception have greater possibilities of developing breast cancer while the incidence decreases after the cessation of the therapy. In fact, it is believed that the use of oral contraceptives before the first pregnancy and for a period of 5 years or more can significantly increase the chance of breast cancer before the age of 36 . However, the current view is that the systematic use of oral contraceptives does not result in a statistically significant increase in breast cancer incidence [8].

Cervical cancer is the second most common type of gynecological cancer, with 528.000 newly diagnosed cases in 2012. Epidemiological data present an increased incidence of the disease in low socioeconomic level populations, due to the lack of information and regular screening.

In developed countries, the application of regular preventive control population has led in reducing the incidence and mortality of the disease [9]. In early stages, cervical cancer is often asymptomatic. For women undergoing screening, the first sign of the disease is usually an abnormal Pap smear test. Symptoms that may present with the extension of the disease are unusual vaginal bleeding, pain during sexual intercourse and malodorous vaginal discharge [10].

Cervical cancer is strongly correlated to human papillomavirus (HPV), particularly with specific strains, such as 6 and 11. HPV is transmitted mainly through sexual intercourse and is a fairly common sexually transmitted disease [11]. High-risk HPV infection is the carcinogenic trigger of over $99 \%$ of cervical cancers. At the same time, over $65 \%$ of healthy volunteers have evidence of past or present infection with HPV. A persistent HPV infection may develop into high-grade cervical intraepithelial neoplasia (HGCIN) or carcinoma [12]. 
Cervical cancer treatment is performed in relation to the progress of the disease, as staged by FIGO (International Federation of Gynecology and Obstetrics) (Figure 2). Several studies have shown that there is a positive correlation between the use of hormonal contraceptives and cervical cancer development. A meta-analysis by Lancet confirms these findings; the risk factor for cervical cancer is increased in women who use contraceptives compared to women who have never received contraceptives. In addition, the risk is elevated depending to the period of time contraceptives were used. The researchers analyzed data on 16,573 women with cervical cancer and 35,509 without cancer by 24 retrospective and prospective studies and observed that the greatest risk for developing cervical cancer presented to women who received contraceptives during the conduction of the study. Women who had interrupted the use presented with lower risk which also decreasing, depending on how long the period of cessation was. Additional results present that when contraceptives where used for less than five years there was no significant increase in risk. On the other hand, the use for 5 years or longer resulted in a significant increase in risk that was almost doubled, compared to women who had never received hormonal contraception. Nevertheless, the risk factor for both groups appears equal, if cancer is not present for a decade after the last use of contraceptives [13].

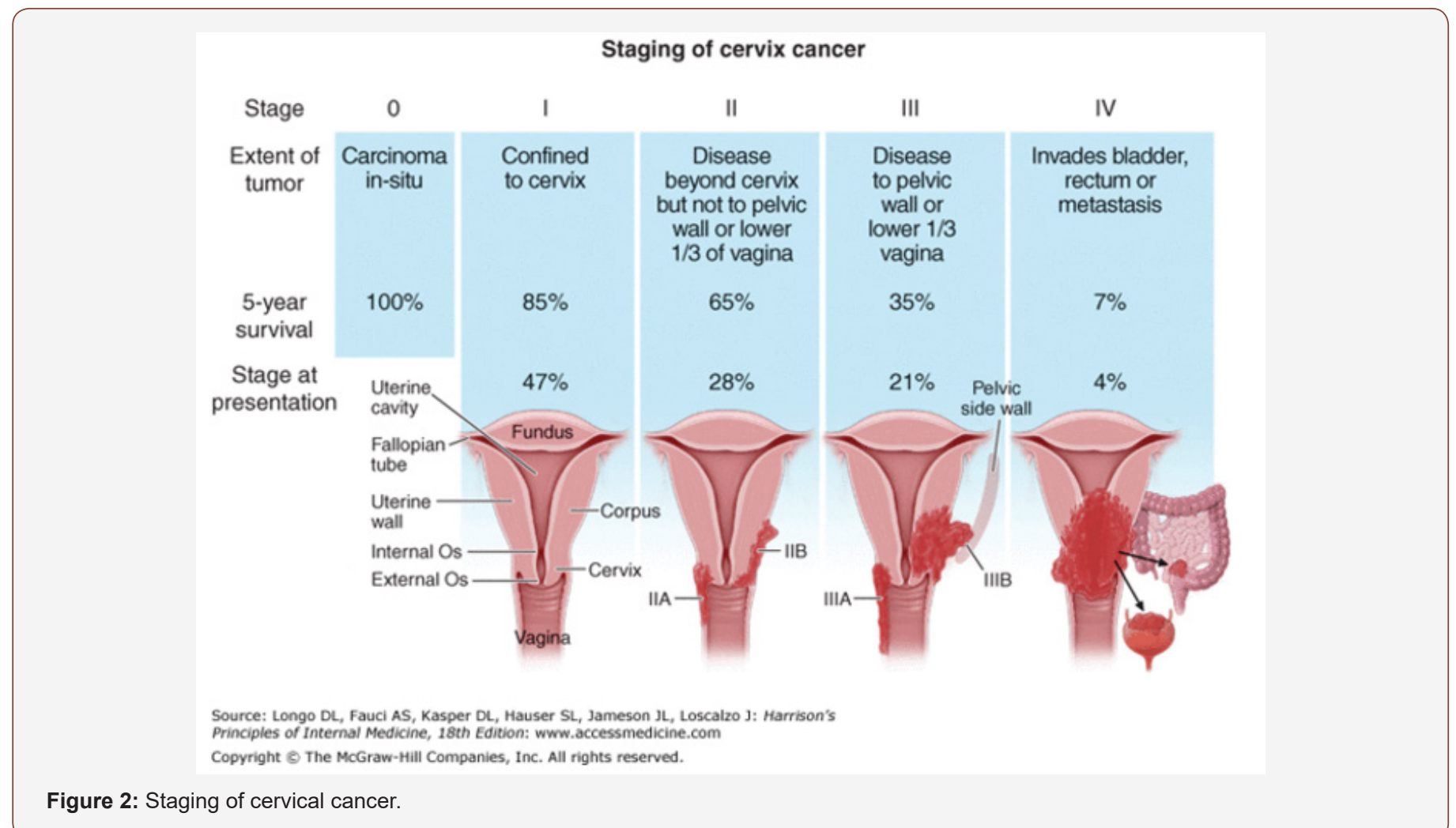

Figure 2: Staging of cervical cancer.

\begin{tabular}{|c|c|c|}
\hline Stage & Extent of disease & 5-year survival \\
\hline I & Limited to body of uterus & $\sim 8 \%$ \\
\hline Ia & no myometrial invasion or $<50 \%$ myometrial invasion & \\
\hline Ib & $>50 \%$ myometrial invasion & \\
\hline II & Limited to body of uterus and cervix & $\sim 75 \%$ \\
\hline III & $\begin{array}{c}\text { Extension to uterine serosa, peritoneal cavity and/or } \\
\text { lymph nodes }\end{array}$ & $\sim 45 \%$ \\
\hline IIIa & $\begin{array}{c}\text { Extension to uterine serosal, adnexae or peritoneal cavity } \\
\text { (positive peritoneal washings/ascites) }\end{array}$ & \\
\hline IIIb & Extension to vagina or parametrium & \\
\hline IIIc1 & Pelvic lymph node involvement & \\
\hline IIIc2 & Para-aortic lymph node involvement & \\
\hline IV & Extension to adjacent organs or beyond true pelvis & $\sim 25 \%$ \\
\hline IVa & Extension to adjacent organs e.g. bladder, bowel & \\
\hline IVb & Distant metastases or positive inguinal lymph nodes & \\
\hline
\end{tabular}

Figure 3: Survival rate staging of cervical cancer. 
Endometrial cancer (cancer of the uterine corpus) is a type of cancer that begins in the uterus. The uterus is the hollow, pearshaped pelvic organ in women where fetal development occurs. The endometrium is the inner lining of the uterus, below the myometrium, which covers the uterine cavity and it is divided into a functional and a basic layer. The main role of the endometrium is the production of a suitable foundation for the implantation of the blastocyst. The basic structural components include glands, the endometrial stroma and mucosal vascular network. This type of cancer occurs fourth among women, worldwide, with increasing incidence in the last decades [14].

Risk factors related to endometrial cancer are the null parity, early menarche, obesity, diabetes mellitus, hypertension, hormone therapy with tamoxifen, estrogenic replacement therapy and hereditary cancer syndromes, such as the Lynch syndrome. This type of cancer is also strongly associated with highly increased rate of pelvic lymph node metastasis [15]. Survival rate varies according to the FIGO staging and it is presented in the table below (Figure 3).

Hormonal factors possess an important role in the risk of endometrial cancer, as exposure to estrogen increases the risk and exposure to progesterone is found to offer a protective effect. A longer interval between menarche and menopause increases the risk of endometrial cancer, as well as the use of estrogen therapy for treatment of menopausal symptoms. It is also known that women with endometrial hyperplasia reported with an increased risk of endometrial cancer [16]. Women who use a hormonal contraceptive are under constant exposure of the endometrium in the synthetic progesterone. The most reliable biological explanation for the protective effect of hormonal contraceptives is the action of progesterone which suppresses endometrial mitotic activity.

The oral combined hormonal contraception (COC) owes its efficacy in suppressing ovulation. Both estrogen and progestogens inhibit the increasing of $\mathrm{LH}$, which is characteristic of ovulation.

Estrogens also suppress FSH and thus, prevent the development of follicles. Continuous use of the $\mathrm{COC}$ leads the endometrium to the continuous exposure to estrogen and progestogens and results to the inhibition of the normal proliferation and is associated with atrophy of the endometrium, a phenomenon which is a biological explanation for the association of hormonal contraceptive with prophylactic effect on endometrial cancer [17].

A large study on the relationship between oral hormonal contraceptives and cancer compared 339.000 women who never used hormonal contraception and 744.000 women as control group, attending follow-up since 1968 for more than 36 years. It appeared that the use of hormonal contraception in relation to the non-use reduces significantly, the risk of endometrial cancer by $10 \%$ (relative risk of 0.47 and $95 \%$ CI 0.27 to 0.81 ) [18].

Ovarian cancer is one of the most difficult diseases affecting women both in terms of diagnosis and treatment. Typical characteristic is the silent proliferation until clinical symptomatology appears. The most important prognostic factor remains the staging of the disease at the time of diagnosis. In early stages, ovarian cancer usually causes no symptoms. Initial signs of ovarian cancer include abdominal discomfort, loss of appetite, nausea, constipation and frequent urination. These symptoms usually occur only when the cancer is already extended [19].

Main therapeutic approach to ovarian cancer represents surgery combined with chemotherapy or radiotherapy. Surgical treatment includes hysterectomy with bilateral salpingo-oophorectomy, pelvic and aortic lymph node dissection. In young patients, some forms of ovarian cancer can be treated with less aggressive surgery regarding fertility preservation [20].

Palliative treatment should also be offered to women suffering from discomforting symptoms, such as pain, vaginal bleeding or bladder and bowel related symptoms. Each case should be treated individually, according to the site of the symptom and the patient's history [21].

Protection provided by oral contraceptives in the development of ovarian cancer is well documented. Although many cases have been to explain the protective effect of combined oral contraceptives (COCs) against ovarian cancer, the exact mechanism remains unknown. Recent surveys show that administration of COCs, even for a short period of time can significantly reduce the risk for ovarian cancer, while protection exists for up to 15 years after discontinuation of COCs. The protective effect of contraceptives is attributed to the inhibition of ovulation or reduction of the impact of pituitary gonadotropins $[22,23]$.

\section{Materials and Methods}

Meeting the aims and the objectives of the study, the most appropriate research approach should be selected. The current study discusses the relation between hormonal contraception and gynecological cancer, as well as the knowledge of patients on contraception and family planning centers. Quantitative method permits the observation and analysis of individual cases objectively and the research is facilitated in organizing in advance, the sample, the data collection and the data analysis.

Literature review was performed through medical and educational internet resources, such PubMed, Cochrane Database, Scholar and medical libraries. The cited references are dated in the last 6 years, with few exceptions in subjects of general knowledge.

The population of the research was current patients of gynecological cancer or with history of the disease and healthywithout personal cancer history women, as control group. The reluctance of some respondents to complete the questionnaire should be mentioned as an initial difficulty, which can be explained by the nature of the questionnaire, which was abolished after personal contact with them and most of the respondents agreed their participation.

Sample size includes 60 cancer patients and 28 healthy women. 6 women refused to participate due to the sensitive subject. Participants were approached in medical facilities, doctors' offices and pharmacies, where patient's medical history was known, on account of the specificity of the needed sample. This means 
that the ratio between cancer patients and healthy women is not representative of the actual situation, nor taken into account in any part of the study. Despite that, the variety among cancer types was completely randomized. The study results cannot be easily generalized since the sample consists of a limited number of specific area respondents; thus, the resulting outcome may not be universally accurate.

Literature review was conducted in order to present the general knowledge around the discussed subject and compare similar studies to the current results. Data collection was performed through written questionnaires, structured with a quantitative self-report technique. One open-type question was included to personalize each participant's personal opinion.

The questionnaire was reviewed and validated by Aegean College Bioethics Committee, in Greek language for the purpose of the research and it is translated for the needs of the study.

Ethical considerations arose due to the sensitivity of the subject were surpassed in favor of the scientific contribution on the discussed topic. Confidentiality is protected as anonymity and privacy were kept in all stages of the research. For this reason, the questionnaires were numbered after the collection from the respondents. This study is subjected to a series of limitations. The questionnaire was based on self-report and some questions request sensitive information. These facts lurk the potential risk of nongenuine responding or presenting the desires and the reflection of the image the participants would like to provide for themselves, rather than reality. In addition, the questionnaire was constructed and used for the first time, so it is considered that equivalent studies must be performed to check the validity and accuracy. Finally, the results are not easily comparable with similar foreign studies, due to different social, economic, educational and political data in each country.

Data analysis was conducted with the use of IBM SPSS Statistics 19 and the results will be presented in tables and graphs, to facilitate the observation and discussion.

\section{Results}

The sample of the research was 88 women, with a variety of ages and lifestyle status, patients with gynecological cancer, or healthy. $51.1 \%$ were women between 41 and 60 years old, $22.7 \%$ were older than 61 years old, 15.9\% were aged between 31 and 40 and the remaining $10.2 \%$ were adults, younger than 30 years old. The greatest percentage of the respondents were residents of small urban cities, with the variation described in Table 1.

Table1: Current disease.

\begin{tabular}{|c|c|c|c|c|c|}
\hline & & Frequency & Percent & $\begin{array}{l}\text { Valid } \\
\text { Percent }\end{array}$ & $\begin{array}{c}\text { Cumulative } \\
\text { Percent }\end{array}$ \\
\hline \multirow{4}{*}{ Valid } & $\begin{array}{l}>100.000 \\
\text { residents(big } \\
\text { urban } \\
\text { center) }\end{array}$ & 13 & 14,8 & 14,8 & 14,8 \\
\hline & $\begin{array}{l}20.000- \\
100.00 \\
\text { residents } \\
\text { (smaller } \\
\text { urban } \\
\text { center) }\end{array}$ & 47 & 53,4 & 53,4 & 68,2 \\
\hline & $\begin{array}{l}2.500-20.000 \\
\text { residents } \\
\text { (small urban } \\
\text { center) }\end{array}$ & 28 & 31,8 & 31,8 & 100,0 \\
\hline & Total & 88 & 100,0 & 100,0 & \\
\hline
\end{tabular}

Educational status varies between highest and basic education, with the majority of the respondents reaching the level of middle education (58\%) and just 3,4\% accomplishing only basic education. Nearly $70 \%$ of the participants were married, with the remaining percent being single or divorced/widowed; $23 \%$ and $9 \%$ respectively. More than half of the respondents had given birth to 1 or 2 children, with the actual percentages concerning parity displaying on Figure 4. In addition, Table 2. presents the actual number and the percentage of the respondents giving birth for the first time.

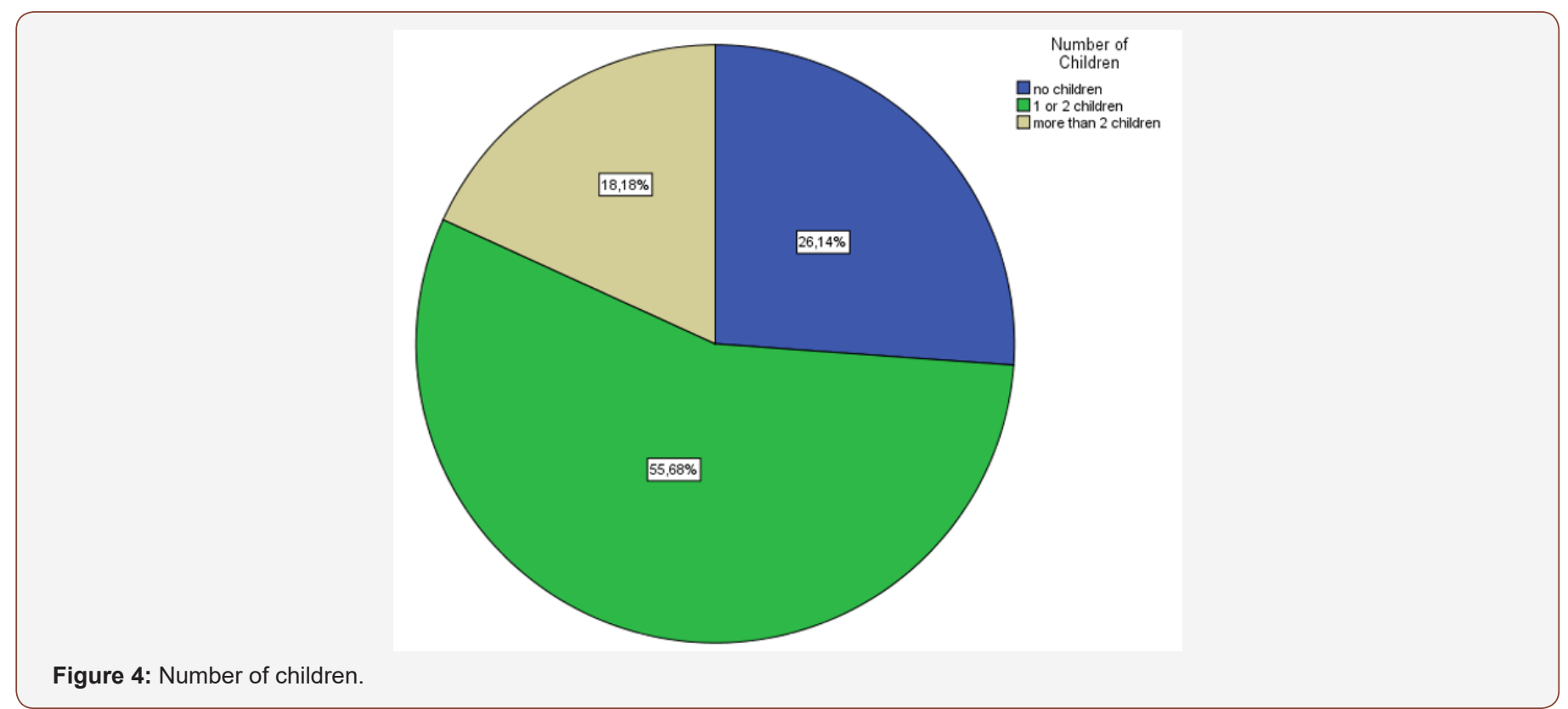


Table 2: Age of giving birth of the first time.

\begin{tabular}{|c|c|c|c|c|c|}
\hline & Frequency & Percent & $\begin{array}{c}\text { Valid } \\
\text { Percent }\end{array}$ & $\begin{array}{c}\text { Cumulative } \\
\text { Percent }\end{array}$ \\
\hline \multirow{7}{*}{ Valid } & No children & 24 & 27,3 & 27,3 & 27,3 \\
\cline { 2 - 6 } & $\begin{array}{c}\text { 18 years old } \\
\text { 18 } \text { old }\end{array}$ & 7 & 8,0 & 8,0 & 35,2 \\
\cline { 2 - 6 } & >35 years old & 1 & 63,6 & 63,6 & 98,9 \\
\cline { 2 - 6 } & Total & 88 & 100,0 & 100,0 & 100,0 \\
\hline
\end{tabular}

As far as age of menarche, $56,8 \%$ of the women were already menstruating by the age of 14 , whereas the percentage had reached the number of 98,9 by the age of 16 . Menopausal age was not yet reached by $37,5 \%$ of the participants, while $17 \%$ entered the period between ages 41-50 years old and the remaining 45,5\% were older than 51 years old. Almost $60 \%$ of the women declared that the commencement of sexual intercourse was later than their 18th birthday and $78,4 \%$ admitted having up to 5 sexual partners.

The following table presents the percentages concerning gynecological cancer on the selected sample (Table 3).

Table 3: Type of cancer.

\begin{tabular}{|c|c|c|c|c|c|}
\hline \multirow{7}{*}{ Valid } & Frequency & Percent & $\begin{array}{c}\text { Valid } \\
\text { Percent }\end{array}$ & $\begin{array}{c}\text { Cumulative } \\
\text { Percent }\end{array}$ \\
\hline \multirow{7}{*}{} & No cancer & 28 & 31,8 & 31,8 & 31,8 \\
\cline { 2 - 6 } & $\begin{array}{c}\text { Breast cancer } \\
\text { Ovarian } \\
\text { cancer }\end{array}$ & 26 & 29,5 & 29,5 & 61,4 \\
\cline { 2 - 6 } & $\begin{array}{c}\text { Cervical } \\
\text { cancer }\end{array}$ & 8 & 14,9 & 15,9 & 77,3 \\
\cline { 2 - 6 } & $\begin{array}{c}\text { Uterine } \\
\text { cancer }\end{array}$ & 12 & 13,6 & 9,1 & 86,4 \\
\hline & Total & 88 & 100,0 & 100,0 & 100,0 \\
\hline
\end{tabular}

The ratio between women who were subjected to radiation or chemotherapy and those who did not was found 2:1, including only the women with personal history of gynecological cancer.
Use of contraception or hormone replacement therapy was not statistically differentiated, as 56,6 of the women were under such treatment at the time of the diagnosis, with the rest being free. 19 women $(21,6 \%)$ revealed that they chose abortion due to complete lack of contraception and 7 more (8\%) due to failure of the contraception method. Smoking statistics are presented in Table 4, with 54,6 of the women being smokers. Healthy diet and alcohol intake results are combined and presented in Table 5. Concerning the age of first Pap smear test, no one of the respondents appeared to have performed one before the age of 18 , whereas $58 \%$ had their first screening between 18-25 years old.

Table 4: Smoking statistics.

\begin{tabular}{|c|c|c|c|}
\hline \multirow{2}{*}{} & \multicolumn{3}{|c|}{ Years of smoking } \\
\cline { 2 - 4 } & Up to 5 & $\mathbf{6 - 1 0}$ & more than 10 \\
\hline $\begin{array}{c}\text { Number of cigarettes } \\
\text { per day }\end{array}$ & & & \\
\hline $0-5$ & $8,3 \%$ & $6,25 \%$ & $4,1 \%$ \\
\hline $6-15$ & $12,5 \%$ & $14,5 \% 7$ & $20,8 \%$ \\
\hline$>15$ & $6,25 \%$ & $6,25 \%$ & $20,8 \%$ \\
\hline
\end{tabular}

Table 5: Healthy diet and alcohol intake results.

\begin{tabular}{|c|c|c|c|}
\hline \multicolumn{2}{|c|}{} & \multicolumn{2}{c|}{ Following a healthy diet } \\
\cline { 2 - 4 } & Absent & 13 & Yes \\
\hline \multirow{2}{*}{$\begin{array}{c}\text { Alcohol intake } \\
\text { per week }\end{array}$} & $\begin{array}{c}\text { Minor (1 glass per } \\
\text { week) }\end{array}$ & 15 & 17 \\
\cline { 2 - 4 } & $\begin{array}{c}\text { Medium (2-5 glasses } \\
\text { per week) }\end{array}$ & 8 & 17 \\
\cline { 2 - 4 } & $\begin{array}{c}\text { Great (more than 5 } \\
\text { glasses per week) }\end{array}$ & 1 & 1 \\
\hline
\end{tabular}

In relation to cancer, $69,3 \%$ presented with positive family history, with only $1 \%$ being unfamiliar with her family's facts. The following figure describes the relation of the respondents to the mentioned family member (Figure 5).

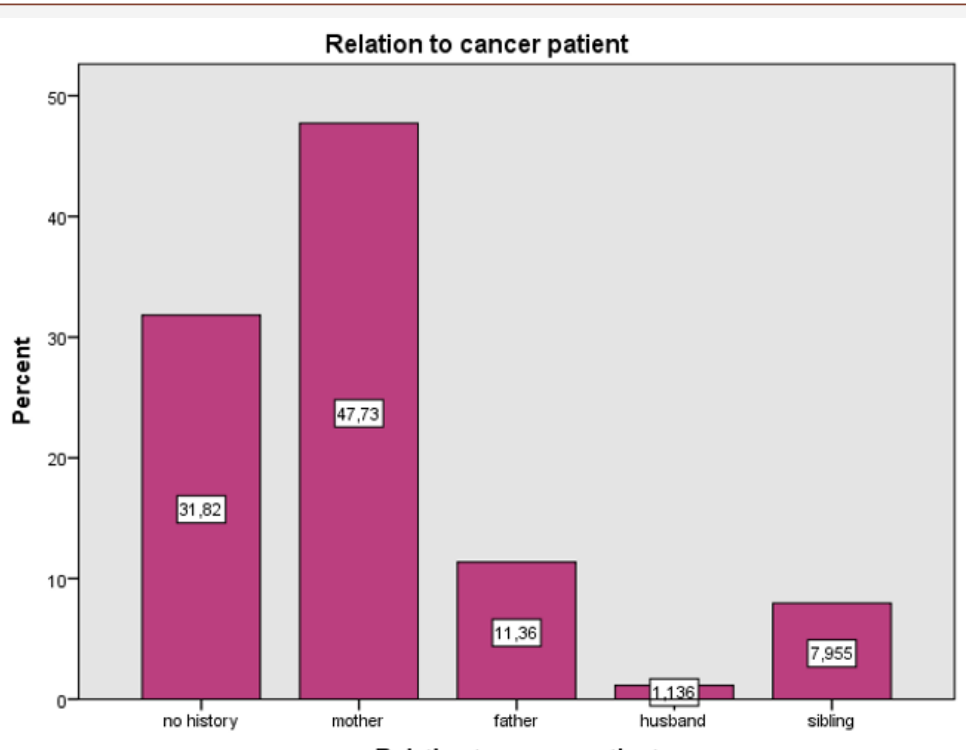

Figure 5: Relation of the respondents to the mentioned family member. 
The following figure describes the current use of contraceptive methods among the participants (Figure 6). 87 out of 88 respondents believe than contraceptive methods should be undertaken, in case the couple does not wish to conceive, with condom declared as the most effective contraceptive method $(80,7 \%)$, followed by contraceptive pill $(15,9 \%)$, intrauterine device -IUD (2,3\%) and fertility awareness method (1,1\%). 65,9\% of the respondents believe that contraceptive pill can re-arrange the menstrual cycle, while 19,3\% disagreed. Half of the women participated in the study believe that contraceptive pill increases the risk for thromboembolism and some types of cancer and should only be administered with doctor's prescription, while $21,6 \%$ and $35 \%$ respectively disagrees.

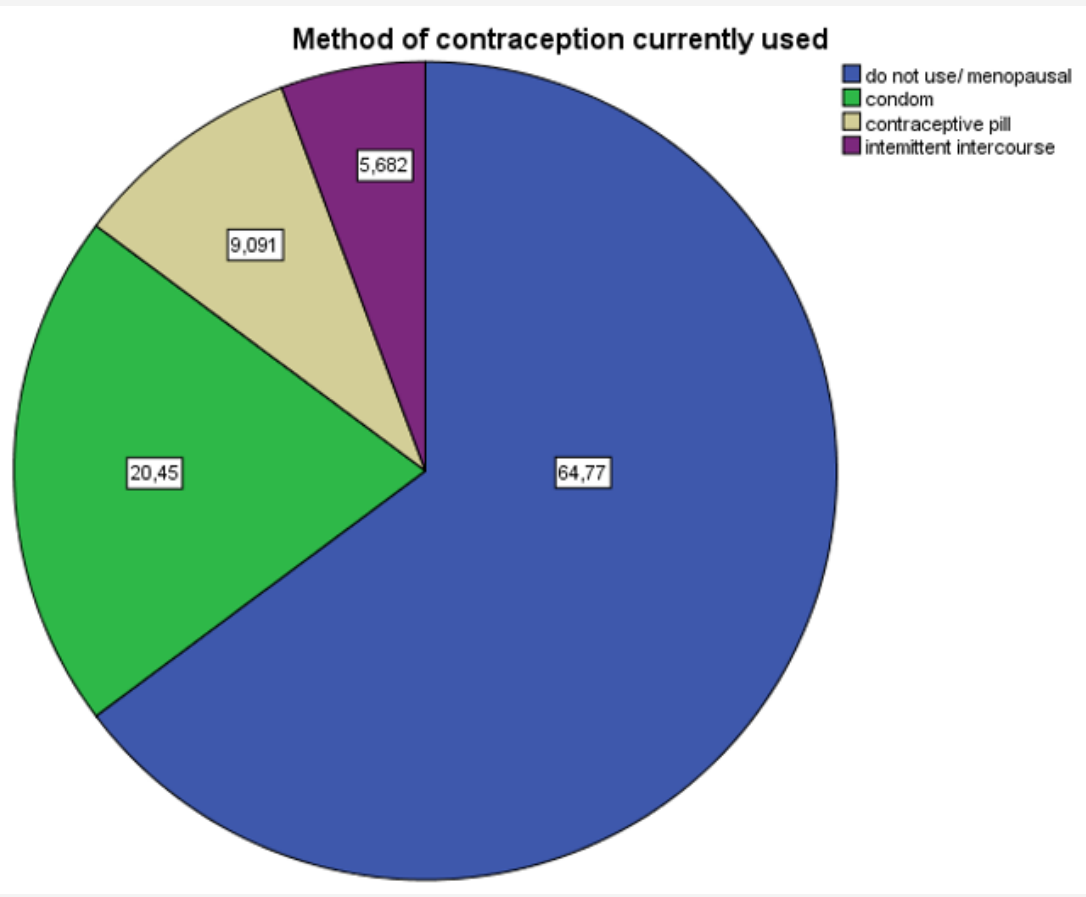

Figure 6: Method of current contraception.

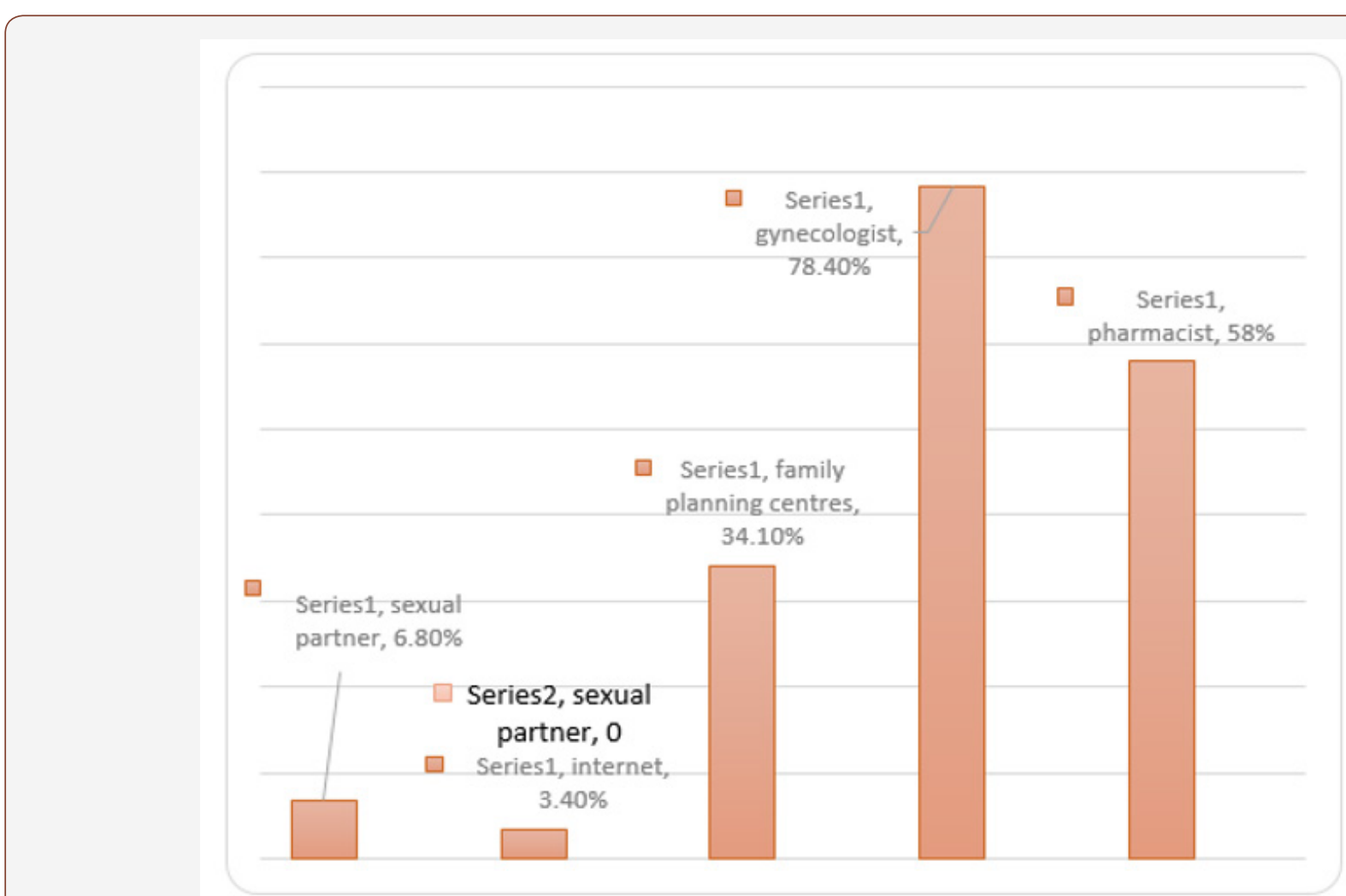

Figure 7: Source of information and contraception. 
Themostcommon reasonfor choosing condom as a contraceptive method appeared to be the protection against sexually transmitted diseases $(36,4 \%)$, while intermittent intercourse is mainly chosen as it not interfering with the pleasure of the contact. The great majority of women believe that both partners are responsible for the use of contraceptive methods, while $14 \%$ believe that men should care for it and the remaining 9,1\% accept full responsibility. Figure 7 presents the results concerning the source of information around contraception. Finally, Table 6. presents the knowledge of the existence of family planning centers among respondents and the incidence of their visit to them.

Table 6: Healthy diet and alcohol intake results.

\begin{tabular}{|c|c|c|c|}
\hline \multicolumn{2}{|c|}{} & \multicolumn{2}{|}{$\begin{array}{c}\text { Have you ever visited a family } \\
\text { planning center? }\end{array}$} \\
\hline & & No & Yes \\
\hline $\begin{array}{c}\text { Do you know about } \\
\text { the existence of family } \\
\text { planning centers? }\end{array}$ & Yes & $12,5 \%$ & \\
\cline { 2 - 4 } & No & $53,4 \%$ & $34 \%$ \\
\hline
\end{tabular}

\section{Discussion}

According to national statistics, breast cancer occupies the second place among cancer-related deaths for women in Greece, after lung cancer; subsequently, the first place among gynecological cancer incidents [24].

European statistics present cervical cancer as the second most common type in women [25]. Ovarian cancer is characterized as rare. The possibility of a woman presenting with ovarian cancer by the age of 85 is $1.6 \%$, while breast cancer risk is 10 times higher [26].

As far as endometrial cancer, the probability for a European woman to develop this type at any point in her life ranges from 1-2\%, with 1 out of 4 women presenting with cancer before menopause [27]. The current study partially meets the national and European statistics. Breast cancer is referred to as the most common type in both studies, whereas cervical cancer was the least commonly met in the current research. Ovarian and endometrial cancer incidence is fairly related in bibliography and present study.

The following table presents the relation between cancer type and subjection to radiotherapy or chemotherapy (Table 7). Breast cancer was most likely to be treated with one of the 2 active treatments, whereas this management was not a common option for endometrial cancer.

Table 7: Relation between cancer type and subjection to radiotherapy or chemotherapy.

\begin{tabular}{|c|c|c|c|c|c|}
\hline \multicolumn{2}{|c|}{} & \multicolumn{5}{|c|}{ Type of cancer } \\
\cline { 2 - 6 } & $\begin{array}{c}\text { Breast } \\
\text { cancer }\end{array}$ & $\begin{array}{c}\text { Ovarian } \\
\text { cancer }\end{array}$ & $\begin{array}{c}\text { Cervical } \\
\text { cancer }\end{array}$ & Endometrial \\
\hline Subjection to & yes & 19 & 11 & 1 & 11 \\
\hline $\begin{array}{c}\text { Radiation/ } \\
\text { chemotherapy }\end{array}$ & No & 7 & 3 & 7 & 1 \\
\hline
\end{tabular}

Chemotherapy can be used prior to surgery, to damage or shrink the cancer cells or after that, to remove any remaining cancer cell and prevent the disease of proliferate.
Radiation therapy is suggested to patients who have undertaken mastectomy or lumpectomy, usually in cases of multiple metastasis or invasion [28]. The role of chemotherapy in the early stages of ovarian cancer remains controversial, whereas it is strongly suggested for advanced stages or epithelial ovarian carcinomas $[29,30]$. Concerning endometrial cancer, studies have failed to prove that radiotherapy demonstrates any remarkable effect on cancerous cells, while there are no sufficient data to describe combined chemotherapy and radiation management, or chemotherapy alone.

More than half of the women with personal cancer history $(56,6 \%)$ declared the use of hormone replacement therapy or hormonal contraception during the period they were diagnosed. Menopausal hormone therapy combining estrogen and progestin intake is not only accused for increasing the risk for breast cancer but also for enhancing the proliferation of cancer cells in adjoining organs (metastasis) [31].

In addition, studies have presented that hormone replacement therapy may be an additional factor in the recurrence of the disease for women who were previously diagnosed with breast cancer [32]. As far as ovarian cancer, research supports that contraceptive pill has beneficial action on women with BRCA1 mutations, by decreasing the risk for cancer in half.

Hereditary breast and ovarian cancer (HBOC) are the type of cancer that is most frequently met among cancer patients with positive gynecological cancer family history. The syndrome arises by the mutation of BRCA1 and BRCA2 genes and it is characterized by the early onset in the patient's age, bilateral breast cancer lesions and multiple primaries. Usually, a first or second degree relative has been diagnosed with similar case [33].

Women with mutation in either of the two genes present 45$85 \%$ risk for breast cancer and $10-45 \%$ risk for ovarian cancer [34].

Regardless the presence of the mutations, ovarian cancer heredity level is described around $20-25 \%$, whereas hereditary breast cancer occupies only 5-7\% [35,36].

Endometrial cancer is characterized by $20-54 \%$ risk, depending on the specific gene mutation [37]. The current research presents high percentages of positive family history, both in healthy women and patients (Table 8).

Table 8: Positive cancer history.

\begin{tabular}{|c|c|c|c|c|}
\hline \multicolumn{2}{|c|}{} & \multicolumn{3}{|c|}{ Positive cancer history in the family } \\
\cline { 3 - 5 } & Yes & No & $\begin{array}{c}\text { I do not } \\
\text { know }\end{array}$ \\
\cline { 3 - 5 } & Count & Count & Count \\
\hline \multirow{4}{*}{$\begin{array}{c}\text { Type of } \\
\text { cancer }\end{array}$} & No cancer & $61 \%$ & $36 \%$ & $3 \%$ (1 case) \\
\cline { 2 - 5 } & Breast cancer & $61 \%$ & $39 \%$ & \\
\cline { 2 - 5 } & Ovarian cancer & $93 \%$ & $7 \%$ & \\
\cline { 2 - 5 } & $\begin{array}{c}\text { Cervical cancer } \\
\text { Endometrial } \\
\text { cancer }\end{array}$ & $75 \%$ & $25 \%$ & \\
\hline & \begin{tabular}{c} 
En \\
\cline { 2 - 5 }
\end{tabular} & $75 \%$ & $25 \%$ & \\
\hline
\end{tabular}


On the other, it was not specific whether the member of the family was diagnosed with a type of gynecological cancer, so conclusions cannot be reached. Nevertheless, maternal positive history reached the highest among percentages (70\%). Prevention and surveillance are key concepts in the management of families with positive cancer history. In reference to a research conducted in Finland, 50\% of cancer cases and $61 \%$ of endometrial hyperplasia would have evolve unattended if there was not routine screening [38].

According to the participants' responses to the current study, $34 \%$ of the women performed their first Pap smear 1-7 years after the commencement of their sexual activity. These two facts cannot be directly comparable, but they can provide an image of the current attitude towards screening compared to the medical facts.

Contraceptive methods provide a long and controversial subject among public discussion and research studies. In U.S.A., $62 \%$ of the women in reproductive age declare the use of contraception. Around $26 \%$ of these women are in favor of hormonal contraceptive pill, whereas $15,3 \%$ prefer male condom; intermittent intercourse is preferred by $4,8 \%$ of respondents [39].

In addition, married women are more likely to use contraception than those who are never married [40]. Concerning the current research, only $13 \%$ of the women aged 18-40 years old admitted not using any form of contraception. $52 \%$ of the women in the same age-group choose male condom, while $17 \%$ of the women were receiving hormonal contraceptive pills.

Unfortunately, there is not sufficient data on the knowledge of women without specific knowledge or field of occupation around contraceptive methods. An international web survey among 4.199 women presented that contraceptive pill is considered the most effective of the contraceptive methods by $31 \%$ of the respondents [41]. On the contrary, $80 \%$ of the participants of the present research believe that condom is the most effective method, followed by contraceptive pill in a percentage of $14 \%$. Only $2,2 \%$ of the women was in favor of the intrauterine device (IUD). In reality, studies have proven that the IUD secreting Levonorgestrel (Mirena) has maximum effectiveness in practice, reaching 99,9\% [42].

It is widely known that common knowledge around contraceptive methods is not as satisfying as it could be. According to a study performed by the UCLA Medical Center, 30, $6 \%$ of women do not know that the contraceptive pill can increase the risk for venous thromboembolism (VTE) [43]. Only half of the respondents of the present research was familiar with the fact that hormonal contraceptive pill may increase the risk for VTE or some types of cancer, while $21,6 \%$ responded negatively and $28,4 \%$ presented no knowledge on the subject. It is interesting that all the women who responded positively, also believed that the contraceptive pill should only be administered with doctor's prescription, while those who had the opposite opinion, did not agree with the necessity of doctor's advice. At the same time, 13,6\% of the participants without knowledge on the adverse effects, still believed that doctor's prescription is not essential. Cultural and religious status are strongly interfering with the beliefs and knowledge of specific population. Surprisingly, in a research conducted among women in Saudi Arabia, only 13, 3\% of the women refused emergency contraception for religious reasons while $73,3 \%$ of the sample were objected to the idea of emergency contraception being administrated without doctor's prescription [44].

Thorough and evidence-based information and guidance concerning contraception is key aspect in the correct use of each method. A study performed among women being counselled by healthcare professionals in 11 different countries showed that $47 \%$ of them concluded that the method they originally planned to use was not suitable for them. Specifically, one out of four women who were considering the use of contraceptive pill were guided to another method [45]. It is satisfying that the women participating in the current research receive information around contraception by healthcare professionals in a percentage between $34,1 \%$ and $78,4 \%$.

As far as family planning is concerned, the present study concludes that even though $46 \%$ of the respondents are informed about the existence of family planning centers (FPC), only $34 \%$ of them have ever visited one.

$86 \%$ of these women were current or past cancer patients seeking for general information and moral support, preparation for labor and aid to the transition to motherhood and information around contraception. $70 \%$ of the women who had never visited a FPC declared that they were not familiar with its existence or its role.

For the rest of them, there was no need for a visit until that moment while 3 of the women expressed that they had difficulty in reaching a center. According to a clinical trial performed in the U.S., only $56 \%$ of the cancer survivors included in the study had received any form of family planning services, without being clear whether they were offered to them or they had to personally seek for them [46].

In a similar study, $73 \%$ of the cancer survivors declared that they did not receive any kind of information concerning fertility preservation, when they were diagnosed, while the majority of them did not personally seek for any kind of information [47]. Another U.S. research among Federally Qualified Health Centers presented how essential is the role of those facilities for women of reproductive age and admitted the necessity of improving the information and care provided by them [48].

\section{Conclusion}

Through the conduction of the research and the composition of the study, there was presented the chance for knowledge and statistics concerning gynecological cancer patients and their involvement with contraceptive methods and family planning to arise, so in national as well as international level. The role of the midwife professes practical and moral support in all women who seek for her help, regarding issues included in her sphere of practice. One of the duties of midwifery profession is to ensure that 
best evidence is used to provide "sound family planning information and advice".

Women with active cancer or cancer survivors should be able to maintain the quality of their lives and be able to return in their normal routine, when it is medically approved, without unnecessary and unpleasant changes.

Literature review has presented that the need for family planning and fertility care and preservation for cancer patients is great and should be approached by both sides.

Continuous surveillance and care concerning recurrence of the disease and implications to other aspects of life medically related or not, should be offered in order to reach the holistic care plan which all healthcare professionals should aim for.

In fact, Fear of Recurrence Therapy, an intervention trialed and suggested in Canada, has presented positive results in the way of improving cancer survivors' quality of life, reducing anxiety and improving psychological functioning.

The American Society of Clinical Oncology and the American Society of Reproductive Medicine consider fertility preservations as a key priority for cancer survivors and suggest that couples should be referred to a fertility specialist who will discuss each case and act accordingly.

As far as the implications of hormonal therapy on gynecological cancer, the results are differentiating according to the specific cancer- hormone combination. The present research highlights the necessity of better educating the total of population around contraceptive methods and family planning, in order to promote health and avoid malpractice.

Sexual health should be promoted by all healthcare specialists, accompanied by patient education and support. Special attention should be given to the sensitive group of cancer patients and cancer survivors who should be offered holistic care to preserve the smooth reintegration in their former lives.

\section{Acknowledgement}

None.

\section{Conflict of Interest}

Authors declare no conflict of interest.

\section{References}

1. World Health Organization (2011) Global health observatory data repository. Number of deaths (World) by cause.

2. Petrucelli N, Daly MB, Feldman GL (2013) BRCA1 and BRCA2 Hereditary Breast and Ovarian Cancer. GeneReviews,

3. Nelson H, Zakcher B, Cantor A, Fu R, Griffin J, et al. (2012) Risk Factors for Breast Cancer for Women Aged 40 to 49 Years: A Systematic Review and Meta-analysis. Ann Intern Med 156(9): 635-648.

4. Misiewicz HM (2012) Fertility Issues of Breast Cancer Survivors. J Adv Pract Oncol 3(5): 289-298.

5. Hulvat MC, Jeruss JS (2009) Maintaining fertility in young women with breast cancer. Curr Treat Options Oncol10 (5-6): 308-317.
6. Valentini A, Finch A, Lubinski J, Byrski T, Ghadirian P, et al (2013) Chemotherapy-Induced Amenorrhea in Patients with Breast cancer with BRCA1 or BRCA2 Mutation. J Clin Oncol 31(31): 3914-3919.

7. Casey P, Faubion S, MacLaughlin K, Long M, Pruthi S (2014) Caring for the breast cancer survivor's health and well- being. World J Clin Oncol 5(4): 693-704.

8. Moorman PG, Havrilesky LJ, Gierisch LM, Coeytaux RR, Lowery WJ, et al. (2013) Oral Contraceptives and Risk of Ovarian Cancer and Breast Cancer Among High-Risk Women: A Systematic Review and MetaAnalysis. J Clin Oncol 31(33):4188-4198.

9. Ferlay J, Soerjomataram I, Ervik M, Dikshit R, Eser S, et al. (2012) Cancer Incidence and Mortality Worldwide: IARC Cancer. Base No 11 [Internet], Lyon, France.

10. NHS (2015) Symptoms of cervical cancer.

11. Gravitt PE (2012) The known unknowns of HPV natural history. J Clin Invest 121(12): 4593-4599.

12. Guo S, Williams-Brown MY, Diaz-Arrastia CR (2012) Cervical Cancer, Tumor Board Review Guideline and Case Reviews in Oncology (17): 183.

13. The Lancet (2007) Cervical cancer and hormonal contraceptives: collaborative reanalysis of individual data for 16,573 women with cervical cancer and 35509 women without cervical cancer from 24 epidemiological studies. Lancet 370(9599): 1609-1621.

14. Hüsing A, Dossus L, Ferrari P, Tjønneland A, Hansen L, et al. (2016) An epidemiological model for prediction of endometrial cancer risk in Europe. Eur J Epidemiol 31(1): 51-60.

15. Mularz A, Dalati S, Pedigo RA (2016) Endometrial hyperplasia and uterine cancer, Ob/Gyn Secrets (30): 135

16. National Cancer Institute (2012) Gynecologic Cancers Portfolio Analysis, Summary of the burden of gynecologic cancers in the US and investments in research by the National Cancer Institute and members of the International Cancer Research Partnership.

17. Stewart FH (2007) Combined Oral Contraceptives, Contraceptive Technology, (11): 197-201, $19^{\text {th }}$ ed, Ardent Media Inc, New York.

18. Hannaford PC, Selvaraj S, Elliott AM, Angus V, Iversen L, et al. (2007) Cancer risk among users of oral contraceptives: cohort data from the Royal College of General Practitioner's oral contraception study, BMJ 335: 651 .

19. Balega J, Sheperd JH (2007) Surgical Management of Patients with Epithelial Ovarian Cancer, Cancer of the Ovary, Cambridge University Press.

20. Reynolds K (2007) What every woman should know about gynecologic cancer, Comprehensive Cancer Center, University of Michigan.

21. Gynecological Cancer Guidelines, Best Clinical Practice. NSW Department of health, 2009

22. Ness RB, Grisso JA, Vergona R, Klapper J, Morgan M, et al. (2001) Oral contraceptives, other methods of contraception and reduced risk for ovarian cancer. Epidemiology 12: 307-312.

23. Greer JB, Modugno T, Allen GO, Ness RB (2005) Shortterm oral contraceptive use and the risk of epithelial ovarian cancer. Am J Epidemiol 162(1): 66-72.

24. Ministry of Health and Social Solidarity, 2016.

25. Executive Agency for Health and Consumers. (2014) European surveillance and control network for cervical cancer in the new statesmembers; AURORA.

26. Greek Anticancer Study, 2016

27. European Society for Medical Oncology (ESMO) (2012) Endometrial Cancer, Information for Patients according to ESMO guidelines.

28. Moran MS, Schnitt SJ, Giuliano AE, Harris JR, Khan SA, et al. (2014) Society of Surgical OncologyeAmerican Society for Radiation Oncology Consensus Guideline on Margins for Breast-Conserving Surgery With 
Whole-Breast Irradiation in Stages I and II Invasive Breast Cancer. Int J Radiation Oncol Biol Phys 88(3): 553-564.

29. Colombo E, Preti F, Landoni S, Carinelli A, Colombo N, et al. (2013) Endometrial cancer: ESMO Clinical Practice Guidelines for diagnosis, treatment and follow-up. Ann Oncol 24 (Suppl 6): 633-638.

30. Ledermann JA, Raja FA, Fotopoulou C, Gonzalez-Martin A, Colombo N, et al. (2013) Newly diagnosed and relapsed epithelial ovarian carcinoma: ESMO Clinical Practice Guidelines for diagnosis, treatment and followup. Ann Oncol 24(Suppl 6): 624-632.

31. Chlebowski RT, Kuller LH, Prentice RL, Stefanick ML, Manson JE, et al. (2009) Breast cancer after use of estrogen plus progestin in postmenopausal women. N Engl J Med 360(6): 573-587.

32. Holmberg L, Iversen OE, Rudenstam CM, Hammar M, Kumpulainen E, et al. (2008) Increased risk of recurrence after hormone replacement therapy in breast cancer survivors. J Natl Cancer Inst 100(7): 475-482.

33. Karlan BY, Berchuck A, Mutch D (2007) The role of genetic testing for cancer susceptibility in gynecologic practice. Obstet Gynecol 110(1): 155-167.

34. King MC, Marks JH, Mandell JB New York Breast Cancer Study Group (2003) Breast and ovarian cancer risks due to inherited mutations in BRCA1 and BRCA2. Science 302(5645): 643-646.

35. Weisman SW, Weiss SM, Newlin AC (2012) Genetic testing by cancer site ovary. Cancer J 18(4): 320-327.

36. Van der Groep P, Van der Wall E, Van Diest PJ (2011) Pathology of hereditary breast cancer. Cell Oncol 34(2): 71-88.

37. Barrow E, Hill J, Evans DG (2013) Cancer risk in Lynch syndrome. Fam Cancer 12(2): 229-240.

38. Auranen A, Joutsiniemi T (2011) A systematic review of gynecological cancer surveillance in women belonging to hereditary nonpolyposis colorectal cancer (Lynch syndrome) families. Acta Obstet Gynecol Scand 90(5): 437-444.
39. Jones RK, Dreweke J (2011) Countering Conventional Wisdom: New Evidence on Religion and Contraceptive Use, New York: Guttmacher Institute.

40. Jones J, Mosher WD, Daniels K (2012) Current contraceptive use in the United States, 2006-2010, and changes in patterns of use since 1995. Natl Health Stat Report 18(60): 1-25.

41. Merck Sharp, Dohme (MSD) (2012) “I Plan On” International Research, $12^{\text {th }}$ Congress of the European Society of Contraception and Reproductive Health (ESC), Athens.

42. Hatcher RA, Trussell J, Nelson AL, Cates W Jr, Stewart FH, et al. (2007) Contraceptive Efficacy, Contraceptive Technology. $19^{\text {th }}$ ed. New York, NY: Ardent Media, Inc.

43. Nelson AL, Rezvan A (2012) A pilot study of women's knowledge of pregnancy health risks: implications for contraception. Contraception 85(1): 78-82.

44. Karim SI, Irfan F, Rowais NA, Zahrani BA, Qureshi R, et al. (2015) Emergency contraception: Awareness, attitudes and barriers of Saudi Arabian Women. Pak J Med Sci 31(6): 1500-1505.

45. Bitzer J, Gemzell-Danielsson K, Roumen F, Marintcheva-Petrova M, van Bakel B, et al. (2012) The CHOICE study: effect of counselling on the selection of combined hormonal contraceptive methods in 11 countries. Eur J Contracept Reprod Health Care 17(1): 65-78.

46. Dominick SA, McLean MR, Whitcomb BW, Gorman JR, Mersereau JE, et al. (2015) Contraceptive Practices Among Female Cancer Survivors of Reproductive Age. Obstet Gynecol 126(3): 498-507.

47. Kim J, Mersereau JE, Su HI, Whitcomb BW, Malcarne VL, et al. (2016) Young female cancer survivors' use of fertility care after completing cancer treatment. Support Care Cancer 24(7): 3191-3199.

48. Wood S, Beeson T, Bruen B, Goldberg DG, Mead H, et al. (2014) Scope of family planning services available in Federally Qualified Health Centers. Contraception 89(2): 85-90. 